\title{
Peer Tutoring in Materials Science
}

\author{
Caroline Baillie, Robin Grimes \\ Department of Materials, Imperial College of Science Technology and Medicine
}

\begin{abstract}
In the Materials Department of Imperial College we have introduced a peer tutoring scheme for the first year subject of crystallography. It is a subject which students find difficult since it involves new concepts, in particularly the use of three dimensional lattices and structures. Formally the subject is taught through lectures, classwork and general tutorial sessions. We have trained peer tutors over two days, to understand the need to draw out students so that they work through and think out for themselves some of the more confusing aspects of the subject. Within a very short period of time, the tutors had developed so that, rather than seeing their role as a surrogate teacher, they now understood their role to be that of a facilitator. The fact that the peer tutors could use real scientific concepts in their role plays helped to provide a focus. It also ensured that the tutors realised that they really could use group process and discussion to solve even technical problems. The scheme, with its possible pitfalls and solutions, is discussed in the context of materials science.
\end{abstract}

\section{Introduction}

Peer tutoring schemes have been successfully implemented in many Universities world-wide to promote student learning ${ }^{1-4}$. Peer tutors help_younger students to learn by holding group sessions in which certain topics are discussed. The aim of the scheme is not to provide text book answers to set problems or even to provide formal supplementary teaching, rather it is the peer tutor's job to act as a focus for the group and thereby make it work for itself. More specifically, the group provides a supportive environment for new students to: test out their understanding of difficult concepts introduced in lectures; gain confidence in dealing with the volume and complexity of material; use the staff run tutorial system effectively; take more responsibility for their own learning; encourage co-operative problem solving methods; promote a deeper approach to learning. It has been shown in some situations ${ }^{5}$ that, hour for hour, tutoring is as effective as teaching by trained teachers. In the Materials Dept. at Imperial a peer tutoring scheme was established in Oct 1997 for the first year crystallography students, with the above aims - focused on the learning of crystallography.

\section{Principals of peer tutoring}

The principles of peer tutoring, as given to the tutors, are as follows:

- Training - two days training required for the tutor to learn effective small group tutoring methods.

- Focus - students in the group ask and answer questions, fielded by the tutor.

- Help new students - to get to grips with University life and studying. 
- Evaluation - the system will be evaluated for its effectiveness in an ongoing manner.

- Support network - supported by the Senior Tutor, IC Education Development lecturer and the course lecturer.

- Attendance - voluntary and confidential.

- Benefits to the students - enables mastery of concepts, develops transferable skills, increases level of performance, gives privacy to practice, make mistakes and build up confidence, working in a collaborative not competitive way, individualised instruction, responding to peers, companionship from tutors, groupwork skills.

- Benefits to the tutor - develops leadership skills, practice in the subject, develop communication skills, personal adequacy, reinforcing knowledge of the fundamentals, experience of being productive, be more involved in the learning process, invaluable training and experience for any job and especially involving teaching (Peer tutors often go on to become academics).

- Usually one session per week/two weeks is held by arrangement between the tutor and allocated students (between five and ten). This may be in an arranged time slot or in students free time.

- Feedback sessions are held once/month with the support team.

\section{Tutor Training}

Peer tutor training is recognised as an important part of the process, however, in many cases this training is conducted as a very general course for many disciplines and the topics considered in the role play simulated tutorials have little in common with the subjects which will be tutored. In the case where an engineering student will have to tutor difficult technical subjects, they gain no confidence and in fact, do not relate well to discussions on, for example, humanities based topics in a simulated tutorial game. Often they express concern that it is not possible to function in this interactive manner with a focus on scientific concepts. Student tutors find it difficult to bridge the gap between the course and the real thing. A similar phenomenon is often the cause of problems with staff development courses.

It has been shown that tutees of trained tutors can do significantly better than tutees of untrained tutors ${ }^{6}$. The training should not be a full scale teacher training and in some instances this has been shown to have little effectiveness ${ }^{7}$. However, some preliminary advice on how to proceed appears to be crucial.

The weekend training course in the Materials Dept. was primarily aimed at helping the prospective tutors understand the need to facilitate (make easier) the learning rather than teach. They were introduced to the concepts of surface and deep approaches to learning as well as characteristics of the context of learning associated with these ${ }^{8}$. There were additionally sessions on group management, what to do with students joining the group, setting up ground rules, what to do in the first session, ice breakers, how to start off, various session strategies as well as ideas on how to help students read actively and think creatively. They are helped to explore good group practice techniques such as probing, brain storming ${ }^{9}$, recording group interactions in order to monitor group dynamics, developing listening and communication skills ${ }^{10}$ and closing techniques. 
The approach to the training was based on experiential learning ${ }^{11}$. The students all take it in turns to role play tutor and students in a scenario with dissenting or silent students and ideas are brainstormed or given in rounds to discuss possible solutions. They then try to put these into practice in their next simulated session.

What seems to have been particularly useful was the use of 'real' problems in context. These tutors were all materials science students who had previously studied crystallography. They were all to tutor crystallography. At first they were very nervous about the idea of 'knowing enough' about the subject in order to answer questions, something we are all very wary of, even as teachers. We gave a very bad mock lecture, making all the kinds of mistakes lecturers can make and then set a tutorial problem. The tutors were immediately asked to launch into a tutorial session and of course tried to teach the subject, again rather badly. However, once we had discussed some of the potential pitfalls of this and asked them to come up with possible solutions, they too took to facilitating extremely well. In fact those students who were least confident about the subject matter were best at redirecting questions for obvious reasons!

The students all agreed that the training was useful, enjoyable and interesting. When asked to write down the most important idea they came away with the responses were:

- The importance of showing students how to learn instead of teaching them the subject

- Communication as a group leading to group work

- Don't teach - and be more open-minded in a group

- Groups skills and learning about each other

- How to develop group dynamics so that tutors don't teach

- Not about teaching and how well and accurately you get the message across but more about learning for the students which depends on how well you get them to interact and think for themselves

- How to bounce questions back and group dynamics

- Alternative ways to teaching tutoring

- I changed my opinion of others - and understand that first perceptions are not always right

The student's suggested the following improvements to the training:

- More opportunities to be tutor - more role plays

- Have a sample of students to practice with

- Appraisals seemed too nice. Positive aspects were accentuated and negative aspects glossed over. Perhaps if something was wrong it could have been pointed out with constructive criticism and then the tutor asked to do it again, praising them on their improvement

- Focus on the reality of how it is going to be - attendance, noise and all other worries

- Crash course on crystallography!

Evidently there remained some concerns about the subject but it was hoped that these might be aided by additional help in the form of: the lecturer and two $\mathrm{PhD}$ students on hand for questions that tutors could not handle, lecture notes with objectives for each lecture and what students' might be expected to learn during the two weeks prior to each tutorial as well as supporting self teaching software (see next section) ${ }^{12}$. 
Regarding the student's performance by the end of the weekend, it was quite remarkable to see such a transition in attitude and perception about the learning process and the development of group skills and leadership qualities.

\section{Setting up the tutorials}

Implementing a peer tutoring scheme involved the usual needs and strategy of implementation required for any innovation in teaching ${ }^{1}$ :

\section{i.Dept./Faculty commitment}

- Good teachers who understand the need for the new programme

- Communication between staff

- Enthusiastic, excited coordinator

- Support from the HOD - ability to start afresh and integrate

- Commitment/support from colleagues

\section{ii.Strategy for implementation}

- Find out what other Universities are doing

- Incorporate assessment and evaluation schemes which are reliable and valid

- Develop a plan for raising support/budget

- Include students in the development

- Hold a pilot of the scheme and evaluate it

- Show how the pilot scheme can be scaled up

- Demonstrate the effect on student learning

- Be aware of the implications

- Disseminate the success of the programme

It is important to base any development on previous experience and where there is a perceived need, i.e. lack of funding for tutors, particular difficulties with a certain subject area etc. The discussions regarding the above issues of implementation were held between the Senior Tutor, the subject lecturer and the Dept. Education Developer. The Senior Tutor was particularly concerned that any scheme would not disadvantage any students, what time it would involve on the students and tutors part, and how the effectiveness would be evaluated. The basis for selecting the students, space, timing and financial support needed to be established. Students were all invited to submit an application and were selected on the basis of their ability to perform in crystallography exams (course lecturer input), their personal attitude and potential leadership and team member qualities (Senior /Personal Tutor input) as well as their willingness and motivation to the scheme.

\section{Evaluating the scheme}

\subsection{Introduction}

The peer tutoring scheme was run throughout the autumn term 1997/1998. Sessions were held once per fortnight and were scheduled into the first year timetable at lunch times. The tutors had use of their own notes from the course two years previous, up-to-date aims and objectives 
and a detailed timetable so that before tutorials they would know what had been covered and its relationship to the remaining parts of the course. In addition, the new "Matter" software crystallography module ${ }^{12}$, which has been designed as a self help programme, was constantly available in the computer laboratory. Tutors were introduced to the computer based teaching environment during the training weekend although their use of the facility was left open ended. A separate evaluation will be carried out with a view to providing more guidance in subsequent years.

The continuing evaluation of the peer tutoring scheme was carried out in three areas: student perceptions by open ended questionnaires, peer tutors perceptions by focus group and lecturer perceptions by observation.

\subsection{Student Perceptions}

Students were surveyed in an open ended questionnaire devised by the peer tutors:

1. What do you feel that you've gained from the peer tutoring scheme?

Some typical responses were:

- Understanding of the course as a whole

- Learnt to attack the problem rather than give up after the first attempt

- Useful help in starting a new subject

- You get to know older people in the Dept and gain additional knowledge

2. What are the aspects you think could be improved about the scheme?

Particularly noted were:

- Better total preparation

- Attendance of fellow tutees

- Could be timetabled at a different time - not lunch hour

- More subjects covered

- Less people

3. Were the meetings too frequent, not frequent enough or just about right?

Most students replied that these were:

- Just about right

4. What teaching methods of the tutor did you find most and least effective

The most common responses suggested:

- Relaxed atmosphere

- If he didn't know things we worked it out as a group 
- We were asked to explain what we thought as a group

- Group discussion

- Asking us to explain why and giving us hints to point us in the right way

5. What features would make you think of the tutorials as unmissable (apart from getting the answers to the problem sheets and the examination paper)

Typical responses were:

- Made you think about crystallography and view the different aspects

- Chance to discuss problems and work on them

- Understanding the principles

- Interesting and fun

- Getting to know older people in the Dept.

- Introduction on how much work to do

\subsection{Peer Tutors perceptions}

The peer tutors were evaluated by focus group in which the tutors were asked to focus on the process and the content of the students' learning, on the approaches to learning and any perceived shift towards a deeper approach in this subject area. They were also asked to reflect on the benefits to their own development.

The following discussion points were noted:

1.What happened in the tutorials?

- The students got out their problems and sat around and talked about them

- I got them to work on the board

- Some sessions were over two hours because they liked it so much

- They explained things to each other

- They seemed to enjoy it

- It encouraged them to think more

- It gave them someone to talk to - they would see you in the hall and talk

- 15 students grabbed me the other day for an extra hour

- Everyone told me they had a better understanding of the course

- Even one who didn't speak much began to talk by the end

2.What could be improved?

- More frequent tutorials

- Too many people in one group and not enough in another even though the groups were even at the start

- More training

- Should do it in other subjects as well

3.How did they benefit from being a tutor? 
- We learned a lot about crystallography!

- How different people learn at different speeds

- Communication skills

- We met the first years

- It was great fun

- Learnt about time management

\subsection{Lecturer's perceptions}

Informal discussions between the course lecturer and both students and peer tutors suggests the scheme has been well accepted. From the attendance records kept by the tutors, it appears that $50 \%$ of the first years attended most of the tutorials with some tailing off at the end. Student grades were certainly better than the previous year however as the student cohort is different it is doubtful if this could be used as a guarantee of success alone. Feedback to the Staff student liaison meeting was that the scheme was a tremendous success and students asked why the first years couldn't have it for other subject areas. Several of the tutorials were observed and they were found to be running smoothly, with peer tutors sitting back allowing students to solve problems themselves. They all demonstrated a very friendly and supportive environment.

\section{Summary}

The peer tutoring scheme established in the Materials Dept. has been successfully implemented and appears to be effective in its aims to help students learn and work better in groups. It has also been demonstrated that there is great benefit for the tutors themselves. As both students and tutors noted that some groups had problems with over subscription and some with poor attendance, it may be necessary in future years to rearrange groups after a week or two. The ongoing evaluation will focus our attention on further possible improvements for the next cohort including the possible need for more frequent tutorials or any extra training. We will also consider the appropriateness of the scheme for other subjects,

\section{Bibliography}

[1] Baillie, C.A., "First year Experience in Engineering Education - a comparative study", to appear in Teaching Science for Technology at Tertiary level, Tornkvist, S., Ed. 1997.

[2] Miller, R., 'Connections: Integrated First year engineering education at the Colorado School of Mines' proc ASEE/IEEE Frontiers in Education Conference 1995 Editors Budny, D., Herrick, R.

[3] Cross, I., Peer support through supplemental instruction for civil engineering students', Engineers' proc Prof Std.s and quality in engineering education Sheffield UK, Ed Bramhall, M., Robinson, I., 1997, p97-102

[4] Magin, D., Churches, A., 'Peer tutoring in engineering design: a case study', Studies in higher Education Vol. 20 No. 11995 p 73-85

[5] Bausell, R.B., Moody, W., B., Waklzl, F., (1972) 'A factorial study of tutoring versus classroom instruction. American Educ. Res. Journal 9 592-7

[6] Conrad E., E., (1975) The effects of tutor achievement level, reinforcement training and expectancy on peer tutoring, Dissertation Abstract 367 4341-4342A University Microfilms No. 76, 1407 PhD University of Arizona [7]Goodlad, S., Hirst, B., 'Peer Tutoring - a guide to learning by teaching', Kogan Page, London 1989

[8] Ramsden, P., 'Learning to teach in Higher Education' Routledge, 1992

[9] Habeshaw, S., Habeshaw, T., and Gibbs, G., 53 Interesting things to do in your seminars and tutorials' 1984 Technical and Educational Services Ltd. Bristol 
[10] The Conflict Resolution Network Commuincation and Listening skills Australia 1990

[11] White, A., Supplemental Instruction Leader Training and Resource Manual

School of Cognitive and Computing Sciences, University of Sussex, 1995

[12]. Materials Science on CD-Rom v2.1, published by Chapman and Hall 1998.

CAROLINE BAILLIE is a lecturer in materials science and engineering as well as education development at Imperial College. She researches aspects of materials science as well as student learning issues in science and engineering areas. She is particularly interested in developing ways of improving student learning which mesh with the present culture and workload of the teachers.

ROBIN GRIMES is a lecturer in the department of Materials. In his research he uses computer simulation to predict the behaviour of inorganic materials, focusing on the effects that dopant ions have on structural and electronic properties. He teaches the crystallography subject presently discussed as a first year core course. 